\title{
THE EFFECT OF CORTISONE ACETATE ON THE ORAL INOCULATION WITH CANDIDA ALBICANS IN THE GERM-FREE MICE*
}

\author{
TAKEJI NISHIKAWA \\ Departments of Dermatology and Microbiology, School of Medicine, \\ Keio University, Tokyo, Japan
}

(Received for publication February 28, 1969)

An experimental model of systemic candidiasis in animals has not been successfully made in the similar manner as that in man which has been produced by the invasion of the candida into the blood stream from the gastrointestinal tract. Animals fed with Candida albicans by oral route could not be infected by them regularly because of the presence of intestinal bacterial flora and the low virulence of $C$. albicans, etc., although several controversial investigations have been reported.,2,3 In an approach to solve this problem, germ-free mice have been introduced to the studies on the experimental candida infection and it was suggested that growth and multiplication of $C$. albicans in the alimentary tract of the germ-free mice are not always closely related with the development of the systemic candida infection. ${ }^{4,5}$

The present investigation was undertaken to determine the role of the corticosteroid hormone, which is ordinarily regarded as one of the resistancereducing-agents of the host, in the infection of $C$. albicans by the oral inoculation in the germ-free mice.

\section{MATERIALS AND METHODS}

Germ-Free Mice. ICR germ-free mice, CD-1 strain, were provided from the Central Laboratory for Experimental Animals, Tokyo. The mice aged 8 weeks on an average and weighing 20 to $25 \mathrm{~g}$, were individually housed in

* Read in part before the 12th Annual Meeting of the Japanese Society for Medical Mycology held in Kanazawa on November 10, 1963. 
metal cages in the Trexler type vinyl isolator (made by Central Laboratory for Experimental Animals) and maintained by the routine gnotobiotic techniques. The details of the techniques employed were described elsewhere. ${ }^{5}$ The mice were given CL-1 mouse pellets and water, both of which had been sterilized by autoclaving at $121^{\circ} \mathrm{C}$ for $20 \mathrm{~min}$. The state of the germ-free mice were periodically checked by the established procedures ${ }^{6}$ for microbial and macroparasitic associates, and no microorganisms could be isolated from all the specimens from the ICR germ-free mice. Furthermore, no mycoplasma (PPLO) could be recovered on the routinely used PPLO media. No cytopathogenic effect could be revealed by the inoculation of the feces of these germ-free mice on primary mice kidney cells.

ICR SPF Mice. About 6 week old ICR SPF mice were used for the studies of sensitivity of cortisone acetate. The mice were supplied from the Japan Clea Co., Tokyo, where they had been bred and maintained under a specific pathogen-free condition. Each mouse was caged separately and fed with CL-1 mouse pellets, which were autoclaved at $121^{\circ} \mathrm{C}$ for $20 \mathrm{~min}$ and with sterile water ad libitum. The mice were maintained in the ordinary experimental animal room.

C. albicans strain. Candida albicans No. 4 was used throughout this experiment. The origin and virulence of the strain, the preparation of inoculum and its transfer into the isolator were just the same as previously described. 5

Oral Inoculation. Candida albicans were cultivated on Sabouraud dextrose agar (Eiken Co., Tokyo) for $24 \mathrm{hr}$ at $37^{\circ} \mathrm{C}$, and $0.1 \mathrm{ml}$ of an appropriate dilution of the suspension was administered into the stomach lumen of the mice through a metal catheter under light ether anesthesia. The inoculum size was quantitatively determined by making pour plate culture with the appropriate dilution of the suspension.

Enumeration of $C$. albicans. Freshly voided feces, contents from the different segments of the alimentary tract and a part of several organs were weighed, put into $5 \mathrm{ml}$ saline and was homogenized with motor-driven glass homogenizer. From the homogenates 10 fold serial dilutions were made and $0.1 \mathrm{ml}$ of appropriate dilutions were spread over Sabouraud dextrose agar plate for detection of $C$. albicans. Colonies were counted after $48 \mathrm{hr}$ incubation at $37^{\circ} \mathrm{C}$.

Drug. The aqueous suspension of cortisone acetate (Japan Merck Co., Tokyo) was unsealed just before use and was sterily transferred into the vinyl isolator in the same manner as the suspension of organisms was 
transferred. To determine the sensitivity of cortisone acetate in mice and to lower the general resistance of mice, $1 \mathrm{mg}$ or $1.5 \mathrm{mg}$ in a volume of 0.04 to $0.06 \mathrm{ml}$ was administered in the dorsal neck region every day or every other day for several times. This dose was determined according to the weight of animals. Changes observed to evaluate the sensitivity of the germ-free mice included the failure to gain weight, microscopical findings in the stomach and death.

Histopathological Examination. The tissues were fixed in $10 \%$ formalin solution and processed by the ordinary procedures. Duplicate sections were stained with hematoxylin eosin (HE) and periodic acid Schiff (PAS) stain. The greater curvature of the stomach and the extended segments of the gut were investigated. The organs examined were the lungs, liver, spleen, kidneys, lymphnodes, heart and brain.

\section{RESULTS}

1. Sensitivity of cortisone acetate in ICR SPF and ICR germ-free Mice.

The first group of mice were injected with $1 \mathrm{mg}$ cortisone acetate per mouse daily for 2 days and every other day for 3 times successively and the second group $1.5 \mathrm{mg}$ for 3 days and every other day for 3 times, in the dorsal neck region of the mouse and observed for the following 3 weeks. On the 21st day after the first injection of cortisone acetate, surviving mice were examined histologically whether an ulcer developed in the stomach or not. As shown in Table 1, germ-free mice tolerated up to $9 \mathrm{mg}$ of cortisone acetate except one mouse that died of the intestinal volvulus, which is a characteristic disease observed in germ-free mice, ${ }^{7}$ while in ICR SPE mice 3 out of 8

Table 1

Sensitivity of cortisone acetate in ICR SPR and ICR germ-free mice

\begin{tabular}{lcccccc}
\hline \multirow{2}{*}{ Status of mice } & $\begin{array}{c}\text { No. of mice } \\
\text { tested }\end{array}$ & \multicolumn{2}{c}{$\begin{array}{c}\text { Dosis of cortisone acetate } \\
\mathrm{mg} / \text { mouse }\end{array}$} & $\begin{array}{c}\text { Mortality } \\
\text { notal (mg) }\end{array}$ & $\begin{array}{c}\text { Ulcus in } \\
\text { within } 3 \text { w. the }\end{array}$ \\
\hline ICR Stomach**
\end{tabular}

* Due to intestinal volvulus.

** Mice were sacrificed at 21 days after the cortisone adminisiration and histological examination was done. 
mice died of wasting and/or secondary infection.

All mice showed temporally weight loss during the injection period, but recovered normal weight gain after the discontinuance of drug administration. On histological examination of sacrificed mice, no ulcer was observed in the forestomach and glandularstomach. Then the effect of cortisone acetate on the stomach in germ-free mice were further investigated. Mice were given $1 \mathrm{mg}$ or $1.5 \mathrm{mg}$ per mouse daily for 2 or 3 times and every other day successively for 3 times. Two mice were killed at each time when mice were given cortisone acetate in a total dose of $2,3,4.5,6,7.5,9 \mathrm{mg}$ and the histological changes in the stomach were investigated.

Comparing with untreated control germ-free mice, hyperkeratosis and atrophy of the epithelium in the forestomach, slight disarrangement, hyperemia, thinning and unevenness of the mucosa of glandularstomach were observed in paralell with the increase of the doses of cortisone acetate. However, no ulcer developed in these mice. These findings were also found in the stomach of ICR SPF mice. The only notable change was the increase of PAS positive layer in the glandular stomach of those mice treated with cortisone acetate.

2. Oral inoculation of $C$. albicans in germ-free mice pretreated with cortisone acetate.

a. Relationship between doses of cortisone acetate and induced systemic infection.

$10^{6}$ cells of $C$. albicans No. 4 were inoculated orally to the mice after the total doses of 0.5 to $4.5 \mathrm{mg}$ of cortisone acetate was reached by the daily administration of $0.5-1.5 \mathrm{mg}$. Cortisone was successively given to 5 groups of mice every other day after the challenge of candida up to the total doses of 1 to $9 \mathrm{mg}$, respectively. C. albicans established themselves in the alimentary tract of these experimental mice and $10^{6}-10^{8}$ cells/g wet weight feces were continuously isolated from the feces.

As shown in Table 2, mice to which more than $5 \mathrm{mg}$ of cortisone acetate were administered in total doses, succumbed to the infection on the 8 th to 16th day after the oral inoculation of candida. Since no sign of systemic infection was found in the group of mice to which 1 to $2 \mathrm{mg}$ cortisone acetate were given, these mice were examined on the 14th day after the oral inoculation searching for the systemic infection.

Figure 1 shows the distribution of candida in the alimentary tract of mice to which less than $2 \mathrm{mg}$ of cortisone acetate were administered in total 
Table 2

Systemic candida infection in germ-free mice induced with cortisone accetate

\begin{tabular}{|c|c|c|c|c|c|c|}
\hline \multirow{2}{*}{$\begin{array}{l}\text { No. of mice } \\
\text { tested }\end{array}$} & \multicolumn{4}{|c|}{ Dosis of cortisone acetate } & \multirow{2}{*}{$\begin{array}{l}\text { Inoculum } \\
\text { size }\end{array}$} & \multirow{2}{*}{$\begin{array}{l}\text { Course } \\
\text { (days) }\end{array}$} \\
\hline & mg/mouse & no. & of inj. & $\begin{array}{l}\text { total } \\
(\mathrm{mg})\end{array}$ & & \\
\hline $\mathbf{3}$ & 0.5 & 1 & 1 & 1 & $10^{6}$ & $\begin{array}{l}\text { All mice survived without } \\
\text { systemic infection }\end{array}$ \\
\hline 3 & 1 & 1 & 1 & 2 & $10^{8}$ & $\begin{array}{l}\text { All mice survived without } \\
\text { systemic infection }\end{array}$ \\
\hline $\mathbf{3}$ & 1 & 2 & 3 & 5 & $10^{8}$ & $8 *, 9^{*}, 11^{s}, 16^{*}$ \\
\hline 5 & 1.5 & 2 & 3 & 7.5 & $10^{8}$ & $8 s, 8^{*}, 9^{*}, 10 s, 10 s$ \\
\hline 5 & 1.5 & 3 & 3 & 9 & $10^{6}$ & $8 s, 8 s, 8 s, 11^{*}, 15^{*}$ \\
\hline
\end{tabular}

s: sacrificed when mouse became moribund.

*: dead.

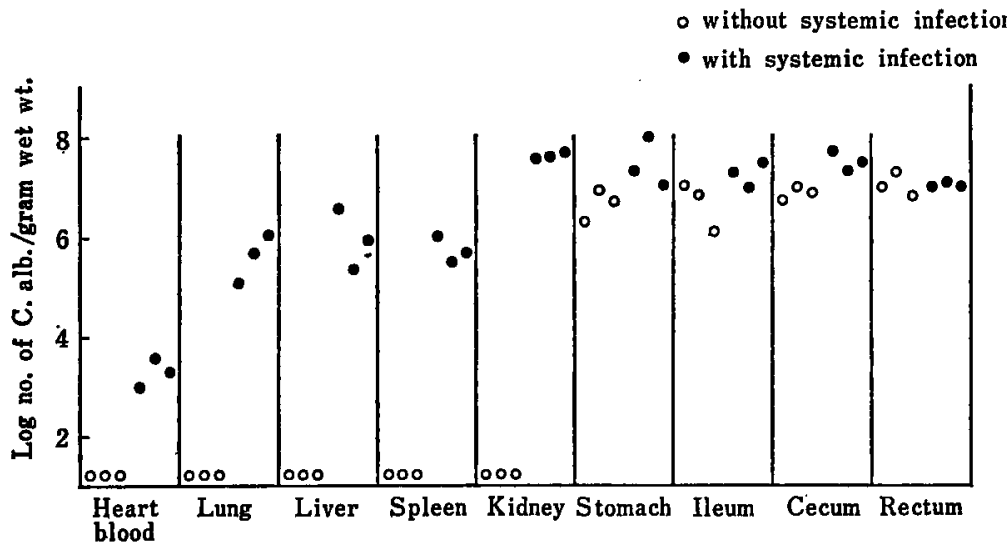

Fig. 1 Enumeration of Candida albicans in cortisone treated germ-free mice with or without systemic infection.

doses, while in infected mice candida were found in all the organs cultured and the kidney showed the most numerous organism recovered. At autopsy, microabscesses were observed in the kidneys, liver, and heart, and again the kidneys showed the most extensive manifestation. On histological examination no significant changes were seen in the epithelium of both glandularstomach and forestomach of mice to which 1 to $2 \mathrm{mg}$ cortisone acetate were administered and showed no systemic infection. However, in the infected group, it was of most interest to find a shallow ulcer with candida invasion in the junction between glandularstomach and forestomach in most of the mice 
(Fig. 2). Furthermore it was found that only the glandularstomach was the portal of entry throughout the gut. As shown in Figs. 3 and 4, candida showed mostly pseudohyphal form in the tissues but some of them remained as yeast form and some showed thick wall as seen in chlamydospores. Pseudohyphal form was predominantly found in the margin of invasion. Candida organisms were observed in the lumina of other parts of the alimentary tract, however, no invasion into the tissues was observed. The histopathological findings in the various organs were consistent with the changes of experimental candida infection by way of intravenous route. Most prominent finding was the abscesses of the kidneys, liver, and heart muscle. Some of the yeast form and budding form candida were observed in the brain tissues with very few cell infiltrations.

b. The early features of invasion in the pretreated germ-free mice after oral inoculation with C. albicans.

Thus the effective doses of cortisone acetate were determined by the previous experiment which made the mice develop the systemic infection. One mg of cortisone acetate was daily injected to 6 mice for 2 days and 2 mice were sacrificed $24 \mathrm{hr}$ after the inoculation for the examination of early changes in the junction of the stomach-forestomach and glandularstomach. The remaining 4 mice had received another $1 \mathrm{mg}$ of cortisone acetate at the third day of inoculation and examined at $120 \mathrm{hr}$ of inoculation.

Table 3

Early features of systemic candida infection in cortisone treated germ-free mice

\begin{tabular}{|c|c|c|c|c|c|c|c|c|c|c|}
\hline \multirow{2}{*}{$\begin{array}{l}\text { No. of } \\
\text { mice } \\
\text { tested }\end{array}$} & \multicolumn{3}{|c|}{$\begin{array}{l}\text { Dosis of cortisone } \\
\text { acetate }\end{array}$} & \multirow{2}{*}{$\begin{array}{l}\text { Time } \\
\text { after } \\
\text { inoc. }\end{array}$} & \multicolumn{3}{|c|}{$\begin{array}{l}\text { Candida albicans } \\
\text { recovered }\end{array}$} & \multicolumn{3}{|c|}{ Invasion of $C$. albicans } \\
\hline & $\underset{\text { mouse }}{\mathrm{mg} /}$ & no. & $\begin{array}{l}\text { total } \\
\text { (mg) }\end{array}$ & & Liver & Kidney & Stomach & $\begin{array}{l}\text { Fore- } \\
\text { stomach }\end{array}$ & Junction & $\begin{array}{l}\text { Glandu- } \\
\text { lar- } \\
\text { stomach }\end{array}$ \\
\hline 2 & 1 & 2 & 2 & $24 \mathrm{hr}$ & $\overline{-}$ & $\overline{-}$ & $\stackrel{+}{++}$ & $\overline{-}$ & $\overline{-}$ & $\overline{-}$ \\
\hline 2 & 1 & 3 & 3 & $72 \mathrm{hr}$ & + & $\overline{t+}$ & $\begin{array}{l}++ \\
++\end{array}$ & $\overline{-}$ & + & $\overline{-}$ \\
\hline 2 & 1 & 4 & 4 & $120 \mathrm{hr}$ & $\begin{array}{l}++ \\
++\end{array}$ & $\begin{array}{l}++ \\
++\end{array}$ & $\begin{array}{l}++ \\
++\end{array}$ & $\overline{-}$ & \pm & + \\
\hline
\end{tabular}

Number of $C$. albicans were enumerated as follows:

$-: 10^{3},+: 10^{3}-10^{4},++: 10^{5}-10^{6},+++: 10^{7}$ (cells/g wet weight)

Invasion of $C$. albicans:

- : No invasion.

+ : Invasion was histologically observed. 
As seen in Table 3, candida were recovered from the liver and kidneys $72 \mathrm{hr}$ after the oral inoculation of candida. At the same time, microscopic lesion of the junction of stomach was observed (Fig. 5). The principal change was leukocytic infiltration in the junction of both stomachs.

\section{DISCUSSION}

Most experiments which have been attempted to determine the pathogenicity of $C$. albicans by the oral inoculation were not enough to explain the relationship between candida and experimental animals. Certain members of intestinal bacterial flora inhibit the growth and multiplication of candida in the alimentary tract of the conventional experimental animals. The agents which reduce the host resistanee such as corticosteroid hormones induce infections. Some of these infections are not of a single infection but of a superinfection of the indifferent non-pathogenic gram-negative bacteria. The inapparent infection manifests itself by the administration of corticosteroid hormoes: These possibilities were not completely ruled out in the previous papers. ${ }^{1,2,3}$

In the present study the experimental candida infection was induced by the oral inoculation with $C$. albicans after treating the germ-free mice with excess doses of cortisone acetate. In this occasion the glandularstomach especially the junction between forestomach and glandularstomach was suggested to play an important role to the "deviated" infection. Significance of the pathological findings in junction was further recognized by observing the leukocytic infiltration and invasion of candida into the junction of both stomachs at $72 \mathrm{hr}$ after the oral inoculation with $C$. albicans. This region was suggested to be initially invaded by candida as a locus minoris. In regard to the action of corticosteroid hormones in the germ-free mice Reed and $\mathrm{Jutila}^{8}$ reported that the mortality following neonatal cortisol administration was lower in the conventional mice given oral Terramycin and in Swiss germ-free mice than in the conventional mice. These results are supposedly due to the absence of intestinal bacterial flora as Reed and Jutila ${ }^{9}$ reported that the mortality of the adult ICR germ-free mice treated with cortisol acetate was increased by monocontamination with Escherichia coli. In the present study the mortality of the adult ICR germ-free mice treated with cortisone acetate was lower than in ICR SPF mice.

Furthermore the steroid ulcer should be ruled out since cortisone has an ulcerogenic property. Rausch-Strooman ${ }^{10}$ noted that the ulcers in the glan- 
dular stomach were produced in rats which were treated with $60 \mathrm{mg} / \mathrm{kg}$ body weight steroid for 30 days, by giving stress, namely 6 days of fasting, even though the ulcer was not observed by steroid administration alone. In the present data the histopathological changes in the germ-free mice treated with several different doses of cortisone were comparable with those found in ICR SPF mice except that the germ-free mice showed the increase of PAS positive layers in the glandularstomach. Therefore the ulcer was apparently formed by the invasion of candida organisms. Phillips and Balish ${ }^{4}$ discussed on the significance of the role of PAS positive material in the gnotobiotic mice to the gastric lesions. Furthermore Savage and Dubos $^{11}$ recently found that a certain strain of yeasts (provisionally classified in the genus Torulopsis) has its preferential growth site in the glandularstomach of CFW germ-free and adult NCS-D mice by the special staining techniques. These reports seem to conform the present study in the point that the glandularstomach played an important role on the growth and invasion of yeasts.

On histopathological changes, C. albicans were polymorphous in forms, such as pseudohyphae, blastospores, budding form and chlamydospore-like-form at the site of invasion. Normally most of the invasive candida grow and invade into the tissues at the right angle to the surface. In the present study, candida tended to grow not so distinctly vertical to the tissues. Furthermore hyphal form was not so predominant. These findings suggest that the lowering of host resistance stands more in the foreground than the virulence of candida itself.

The difference of the strains in the virulence of $C$. albicans and the kinds of corticosteroid hormones are the other important factors which determine the induced systemic infection. We could not observe any systemic infection in the similar experiment using $C$. albicans No. 13 (a stock strain at the Department of Bacteriology, University of Tokyo) in the same ICR germ-free mice. ${ }^{12}$ No pathogenicity of C. albicans No. 4 was observed when predonisolone was administered in mice who harbored this strain as a monocontaminant for a long time (unpublished data). The experiment is of so small scale due to the difficulties in getting and rearing germ-free mice at the present time that more possibilities remain to be solved in the future.

Several factors, acting either alone or in combination, may be important in the development of systemic candida infection in humans. According to Louria ct al ${ }^{13}$ debilitating diseases, antibiotics, adrenal steroids, indwelling intravascular catheter, frequent-intravenous injections, direct access to 
the heart valves at cardiac surgery, and diabetes are enumerated as those factors. Symmers ${ }^{14}$ also suggested that the treatment with corticosteroids and cytotoxic compounds in patients with diseases that lower resistance to infection may predispose septicaemic candida infection. It is, of course, hazadous to apply the results of animal experiments directly to the clinlcal infection in humans. However, the present data indicate that patients receiving corticosteroid hormones are probably more susceptible to disseminated infection. In that occasion, the stomach might play some role as a portal of entry of candida organisms.

\section{SUMMARY}

There was no macroscopic or microscopic ulcer found in the stomach of ICR germ-free mice even when they were treated with relatively large doses of cortisone. When the germ-free mice were orally inoculated with $C$. albicans combined with subcutaneous administration of cortisone acetate with the doses of more than $5 \mathrm{mg}$, shallow ulcer developed at the site of the junction between forestomach and glandularstomach in the majority of the cases. In the base of ulcer, candida showed not only hyphal form but also other various forms. Polymorphonuclear leukocytic infiltration with candida organisms was observed at the site of the junction of the forestomach and glandularstomach shortly after oral inoculation with $C$. albicans. It was considered that the development of ulcer was secondary to the affection of candida. These results indicate that the lowering of the host resistance play an important role on the developement of systemic candida infection.

\section{ACKNOWLEDGEMENT}

The author wishes to express his hearty thanks to Professor S. Sasaki, Department of Microbiology, and Professor H. Hatano, Department of Dermatology for their suggestions and encouragement during the course of this study. He also wishes to thank Professor Y. Nishiyama, Department of Pathology, Kitasato University, for his helpful discussions on interpreting the histopathological findings and to Dr. T. Nomura. Central Laboratory for Experimental Animals, for supplying the precious germ-free mice.

\section{REFERENCES}

1. Iwata, K. and Matsuda, A. (1962) Fluctuation of microbial flora in the intestinal 
tract of mice during bacterial infection and its significance in establishing bacterial or mycotic infections. Nisshin Igaku $49: 631-638$. (in Japanese)

2. Kubo, I., Hori, M., Niitani, H., Yokoyama, I., and Takemoto, T. Studies on the pathogenesis of candidiasis. In Studies on Candidiasis in Japan edited by Research Committee of Candidiasis. Osaka Univ., Osaka, Japan, 145-152, 1961.

3. Tanaka, S. (1961) Studies on the mechanism of mycotic infection. Japan. J. Med. Mycol. 2: 179-185. (in Japanese)

4. Phillips, A.W. and Balish, E. (1966) Growth and invasiveness of C. albicans in the germ-free and conventional mouse. Appl. Microbiol. 14: 737-741.

5. Nishikawa, T., Hatano, H., Ohnishi, N., Sasaki, S., and Nomura, T. Establishment of $C$. albicans in the alimentary tract of ICR germ-free mice and antagonism with $E$. coli after oral inoculation. (Submitted for publication)

6. Wagner, M. (1959) Determination of germ-free status. Ann. N.Y. Acad. Sci. 78: 89-101.

7. Lucky, T.D. Germfree life and gnotobiology. Acad. Press Co., New York and London, 344-349, 1963.

8. Reed, N.D. and Jutila, J.W. (1967) Wasting disease induced with cortisol acetate. 1. Studies in germ-free and conventionally reared mice. J. Immunol. 99: 238-245.

9. Reed, N.D. and Jutila, J.W. (1965) Wasting disease induced with cortisol acetate. Studies in germ-free mice. Science 150: 356-357.

10.' Rausch-Stroomann, J.G. (1965) Tierexperimentelle Untersuchungen zur Frage des Steroidulcus. Zeitschrift gesamt. Exp. Med. 139: 566-573.

11. Savage, D.C. and Dubos, R.J. (1967) Localization of indigenous yeast in the murine stomach. J. Bacteriol. 94: 1811-1816.

12. Nishikawa, T., Olnishi, N., and Sasaki, S. The effect of cortisone acetate in the mice with a monoflora of Candida albicans. (In Japanese) (Submitted for publication)

13. Louria, D.B., Stiff, D.P., and Bennet, B. (1962) Disseminated moniliasis in the adult. Medicine 41: 307-329.

14: Symmers, W.S.T.C. Septicaemic candidosis. Symposium on candida infections, E \& S. Livingstone Ltd., Edinburgh and London, 196-213, 1966. 


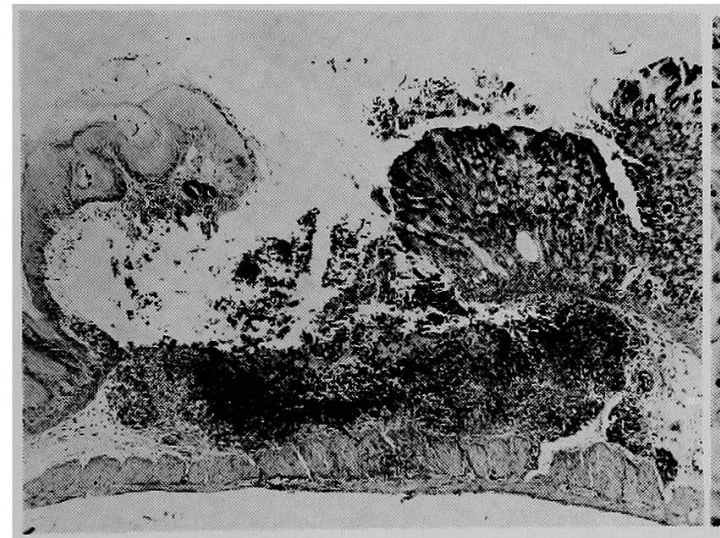

Fig. 2

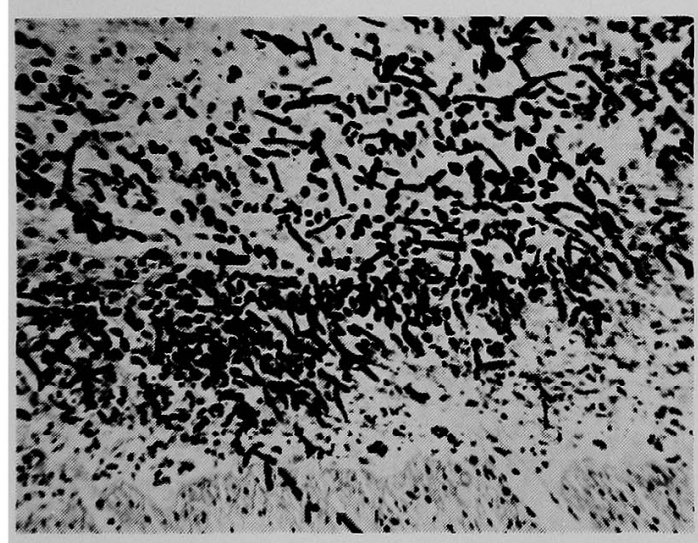

Fig. 4

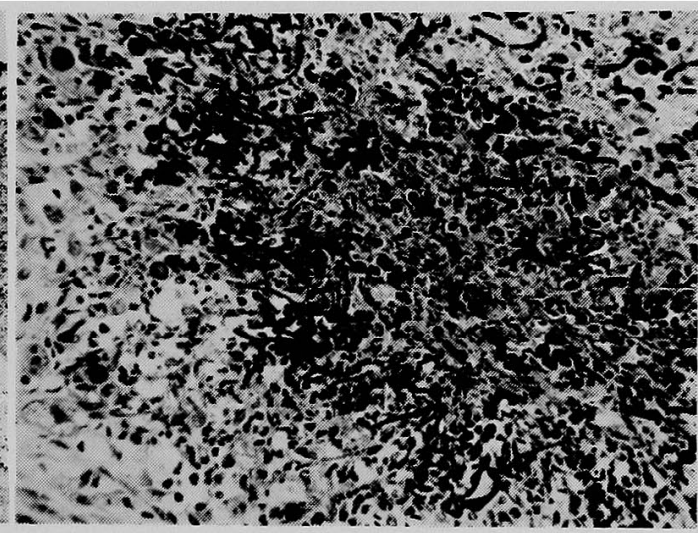

Fig. 3

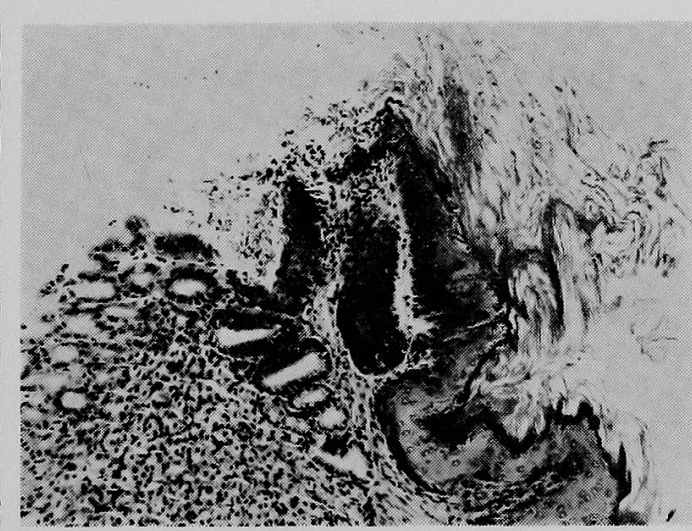

Fig. 5

Fig. 2. Ulcer in the junction between forestomach and glandularstomach. PAS $\times 70$.

Fig. 3 \& 4. Various forms of C. albicans in the base of ulcer. PAS $\times 400$.

Fig. 5. Leukocytic infiltration associated with small numbers of candida at the junction of both stomach. $72 \mathrm{hr}$ after the oral inoculation with $C$. albicans in germ-free mice. HE $\times 100$. 